Revue

Revue de l'histoire des religions

de Ihistoire

des religions

$3 \mid 2018$

Varia

Georges VAjDA, Pensées médiévales en hébreu et en arabe. Études (1931-1981), réunies et introduites par Elisa CODA

Paris, Librairie philosophique J. Vrin («Études musulmanes », 49), 2016

Dan Arbib

\title{
OpenEdition
}

Journals

Édition électronique

URL : http://journals.openedition.org/rhr/9053

DOI : 10.4000/rhr.9053

ISSN : 2105-2573

Éditeur

Armand Colin

Édition imprimée

Date de publication : 1 septembre 2018

Pagination : $549-551$

ISBN : 978-2-200-93188-9

ISSN : 0035-1423

Référence électronique

Dan Arbib, «Georges VAJdA, Pensées médiévales en hébreu et en arabe. Études (1937-1987), réunies et introduites par Elisa Coda », Revue de l'histoire des religions [En ligne], 3 | 2018, mis en ligne le 01 septembre 2018, consulté le 15 janvier 2021. URL : http://journals.openedition.org/rhr/9053 ; DOI : https://doi.org/10.4000/rhr.9053

Ce document a été généré automatiquement le 15 janvier 2021.

Tous droits réservés 


\section{Georges VAJDA, Pensées médiévales en hébreu et en arabe. Études (1931-1981), réunies et introduites par Elisa CODA}

Paris, Librairie philosophique J. Vrin («Études musulmanes », 49), 2016

\section{Dan Arbib}

\section{RÉFÉRENCE}

Georges VAjDA, Pensées médiévales en hébreu et en arabe. Études (1931-1981), réunies et introduites par Elisa CODA, Paris, Librairie philosophique J. Vrin («Études musulmanes », 49), 2016, 346 p., $24 \mathrm{~cm}, 35 €$, ISBN 978-2-7116-2733-2.

1 Le nom de Georges Vajda (1908-1981) n'est évidemment pas à présenter aux lecteurs de la Revue de l'histoire des religions : ses études comme sa méthode ont ouvert des voies encore arpentées par les chercheurs en matière de pensées juives et arabes au Moyen Âge. Il faut donc se réjouir de voir réunies ici nombre d'études classiques et jusqu'à présent d'accès difficile, efficacement introduites par un avant-propos dû à l'éditrice du volume, E. Coda (p. vII-XXII).

2 Le recueil se divise en deux parties : une première rassemble une dizaine d' « études judéo-arabes» (p.1-159), dont des textes d'une remarquable ampleur (par exemple l'étude sur "Les idées théologiques et philosophiques d'Abraham bar Hiyya", p. 169-197) ; la seconde propose seize textes de natures plus diverses, allant d'une série de «brèves notes " ("Brèves notes sur le Risāla fì l-'ulūm d'Abū Ḥayyān al-Tawhịīī», série de suggestions d'améliorations à l'édition de M. Bergé, Épître sur les sciences, Risāla fi l-ulūm d'Abū Hayyān al-Tawhīì̄ initialement publiée dans le Bulletin d'Études Orientales, 18, 1963-1964, p. 241-298, reprises ici p. 267-270) à des notices de plus grande ambition ( De Philon aux scolastiques. Origine et croissance de la philosophie religieuse ", p. 202-216). Cet ensemble est copieusement complété par un "Index des manuscrits » (p. 325-326), un « Index des auteurs anciens » (p. 327-334), un « Index des 
auteurs modernes» (p.335-338), ainsi qu'un «Glossaire des termes techniques (338-342) et une notice précisant l’« Origine des textes» (p. 342-344).

3 Est-il encore utile de rappeler les traits caractéristiques du travail de G. Vajda, héritier des enseignements de Lajos Blau (1861-1936), Bernát Heller (1871-1943), Louis Massignon (1883-1962), Jean de Menasce (1902-1973) ou Henry Corbin (1903-1978)? L'avant-propos s'acquitte fort bien de cette tâche, et nous ne pouvons qu'y renvoyer en insistant néanmoins sur deux ou trois traits de sa méthode, traits constants malgré la longue durée sur laquelle s'échelonnent ces textes (1931-1981). D'abord, le caractère de grande probité philologique qui fut toujours le sien. Ces textes en témoignent: enseigner l'histoire des pensées médiévales en hébreu et en arabe, parfois en grec ou en latin, ce fut d'abord exhumer les manuscrits, les traduire, les dater, les contextualiser : reprendre toute question «à partir du document, et du document seul » (p. 272). Nulle lecture ne se dispense de pareil point de départ ; mais aussi, nul érudit n'y stationne ! Car ce qui surprend toujours, c'est l'effet pour la pensée et pour le penseur d'une enquête philologique au premier abord peu spéculative : morale de la prudence, de la critique, de l'autocritique même (voir p. 272). Mais justement, Vajda enseigne que c'est tout un que de comprendre scientifiquement et penser correctement. André Chouraqui marquait nettement cette solidarité dans son autobiographie : «Il [Vajda] n'admettait aucun à-peu-près dans l'analyse grammaticale ou historique d'un texte qu'il fallait d'abord situer dans son contexte chronologique, géographique et spirituel. Auprès de lui, la Bible s'éclairait d'une tout autre lumière, plus dense, plus vraie que celle dont l'auréolait la piété chrétienne ou rabbinique » (L'amour fort comme la mort, Paris, Robert Laffont, 1990, p.160-161, cité ici p.x) - de quoi faire comprendre la sévérité aussi ironique qu'extrême de G. Vajda devant la bibliographie sélective de Benjamin Gross, Le messianisme juif (Paris, 1969) : «Il serait malséant de notre part de faire état de certaines omissions de la bibliographie ; elles ont été inspirées, nous n'en doutons pas un instant, par les intérêts supérieurs de la possession de la vérité et d'une spiritualité sans tache » (Revue des études juives, 128, 1969, p. 422, cité ici, p. XXI, n. 80). Dont acte. On insistera également sur la grande diversité des auteurs étudiés : littérature rabbinique, kabbale, néoplatonisme juif, philosophie islamique, etc. Le titre du recueil n'eût pu être mieux trouvé : non point Pensée médiévale..., mais Pensées médiévales : il n'y aura point ici une pensée médiévale mais une "diversité rebelle » (pour reprendre la belle expression de Paul Vignaux) de pensées, diversité irréductible à toute opération de synthèse forcée ou caricaturale. Que la pensée juive présentât une forte spécificité qui justifiât la publication, par G. Vajda précisément, d'une Introduction à la pensée juive du Moyen Âge (Paris, 1947) est une chose - conviction profonde validée par les résultats de l'érudition (p.XII-XV) -, mais que l'étude doctrinale des sources juives, chrétiennes et islamiques appelle nécessairement synthèse ou unification, c'en est une autre: le caractère volontairement analytique de la démarche de Vajda au contraire y répugne (cf. G. Vajda, L'amour de Dieu, p. 8-9, n. 36, cité ici p. XV, n. 45). Il ne s'agira pas non plus de tout confondre sous le pseudo-concept indéterminé de philosophie, puisqu'aussi bien il conviendra d'abord d'interroger le rapport d'autres pratiques intellectuelles, et d'abord de la théologie, à la philosophie, quitte à confirmer ledit rapport, par exemple dans le cas de la pensée juive médiévale (p.XII, n. 31). Quant aux résultats de cette méthode, inutile non plus d'y insister : examen à nouveaux frais des positions karaïtes (rappelons les cinq études sur Qirqisânî datées de 1945-1963, dont la première, sur « La magie, la mantique et l'astrologie selon le Livre des lumières et des vigies ", est reprise ici, p. 47-80), renouveau des études saadianiques (renvoyons à la synthèse classique sur 
"Le commentaire de Saadia sur le Séfer Yeçîra », p. 27-45), etc. - tous résultats que les érudits éprouvent encore, mais qui comptent moins, si l'on ose dire, que le geste qui fut celui de G. Vajda : ouvrir ou rouvrir certaines pistes avec une probité philologique impeccable et une érudition impitoyable.

4 Un mot pour finir sur la présentation matérielle de ce recueil : regretter le grand nombre de coquilles (de nombreuses lettres sont tout simplement manquantes) ne serait pas injuste, mais manquerait quelque peu de décence devant, tout de même, l'exceptionnelle réussite formelle du volume : l'éditeur ne s'est pas contenté d'abouter purement et simplement les textes dans la forme de leur version originale, au grand mépris de la cohérence esthétique de l'ensemble, il en a procédé à l'homogénéisation complète et a mis en place une double pagination, la pagination du présent recueil se doublant, en marge, de la pagination de l'article dans sa version originale. On ne déplorera donc pas ici l'effet de rupture dans l'histoire du commentaire souvent suscité par les rééditions d'études classiques selon une pagination totalement nouvelle, pas plus qu'on ne soupirera après l'effet de rapiéçage parfois produit par la jonction cavalière de communications de langue, de présentation et de typographie différentes. D'un tel soin, d'une telle attention apportée à la commodité du lecteur, il faut féliciter l'éditrice (E. Coda) et l'éditeur (Vrin).

\section{AUTEURS}

\section{DAN ARBIB}

École normale supérieure, République des savoirs. 